\title{
A PRECARIZAÇÃO DO TRABALHO DOCENTE NAS INSTITUIÇÕES DE ENSINO SUPERIOR DO BRASIL NESSES ÚLTIMOS 25 ANOS* $^{*}$
}

\author{
Antônio de PÁdua Bosi*
}

\begin{abstract}
RESUMO: Este artigo discute a precarização do trabalho docente nas instituições de ensino superior (IES) do Brasil, no período de 1980 a 2005. Tomando como referência o processo de mercantilização da educação superior, busco identificar e problematizar os principais aspectos da precarização do trabalho docente: (a) o crescimento da força de trabalho docente ocorrido, principalmente, no setor privado e em novas universidades estaduais, em que as condições de trabalho e de contrato existentes geralmente são precárias; (b) a mercantilização das atividades de ensino, pesquisa e extensão nas IEs públicas; e (c) a adoção de critérios exclusivamente quantitativistas para a avaliação da produção do trabalho docente e suas conseqüências.
\end{abstract}

Palavras-chave: Trabalho docente. Precarização. Educação superior.

\section{THE PRECARIZATION OF THE TEACHING WORK IN HIGHER EDUCATION INSTITUTIONS IN BRAZIL OVER THE LAST 25 YEARS}

ABSTRACT: This article brings a discussion about the precarization of the teaching work in higher education institutions in Brazil from 1980 to 2005 . Taking the commercialization process in higher education as a reference, I try to identify and question about the main aspects of the teaching work precarization: (a) the growth of the teaching work force, mainly in the private field and

\footnotetext{
* Este texto é resultado parcial da pesquisa Trabalho precarizado no Brasil contemporâneo, financiada pelo CNPq. Trata-se de pesquisa que investiga os nexos entre ocupaçôes consideradas "formais" e ocupaçōes consideradas "informais" à luz das atuais mudanças no mundo do trabalho.

** Doutor em História e professor adjunto nos cursos de Graduação e de Mestrado em História da Universidade Estadual do Oeste do Paraná (UNIOESTE). E-mail: bosi@certto.com.br
}

Educ. Soc., Campinas, vol. 28, n. 101, p. 1503-1523, set./dez. 2007 
A precarização do trabalho docente nas instituiçôes de ensino superior do Brasil...

at new state universities, where the present working conditions are generally precarious; (b) the commercialization of education, research and extension activities at public higher education institutions; and (c) the adoption of exclusively quantitative criteria for evaluating teaching work production and its consequences.

Key words: Teaching work. Precarization. Higher education.

\section{Introdução}

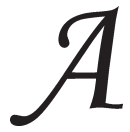

$s$ pesquisas sobre as recentes mudanças no mundo do trabalho (reestruturação produtiva, flexibilização da legislação trabalhista, precarização do trabalho etc.) constituíram um campo temático multidisciplinar bastante rico. No caso do trabalho docente, a sociologia, o serviço social, a saúde e a educação, principalmente, têm esclarecido sobre as diversas dinâmicas de precarização vivenciadas na docência do ensino fundamental e médio e na formação de professores, revelando como a reestruturação produtiva atingiu o fazer dos professores (Oliveira, 2004; Santos, 2004; Augusto, 2005). De outro modo, os estudos sobre a precarização do trabalho docente nas instituições de ensino superior (IES) no Brasil não são numerosos e, geralmente, atêm-se à dimensão da flexibilização das relações contratuais de trabalho (Oliveira, 1996; Pinto, 2000 e 2002; Dal Rosso et al., 2001; Inácio \& Wagner, 2003), discutindo, pouco ou quase nada, as transformações experimentadas na rotina do trabalho acadêmico (ensino, pesquisa e extensão). Mesmo no caso de outros países da América Latina, a tendência tem sido a de considerar a precarização do trabalho docente nas universidades apenas como flexibilização dos direitos e contratos trabalhistas (Gentili, 2005). Reconhecendo essa lacuna como um desafio, o presente artigo tem como objetivo identificar e analisar as mudanças ocorridas no mundo do trabalho docente nas IES do Brasil, com base, principalmente, no exame sobre a constituição dessa força de trabalho nesses últimos trinta anos e o exercício das atividades de ensino, pesquisa e extensão.

Assim, as referências iniciais que revelam a existência de um processo de precarização do trabalho docente nas IES - e que motivaram esse estudo - foram extraídas de farta bibliografia acerca da mercantilização da educação superior (Pinto, 2002; Amaral, 2003; Chaves, 2005; Silva, 2005) e de uma percepção generalizada de professores 
universitários que têm acusado o aumento, a intensificação e a desvalorização de seu trabalho. Nesse sentido, além dos diversos tipos de trabalho disciplinados por contratos caracterizados pela ausência de muitos direitos trabalhistas e sem qualquer estabilidade, considerei como precarização do trabalho docente a rotina das atividades de ensino, pesquisa e extensão que compóe propriamente o fazer acadêmico. Foi com base nessa realidade que tentei problematizar a situação atual do trabalho docente no Brasil, articulando dados relacionados às IES dos setores público (federal, estadual e municipal) e privado (comunitárias, confessionais e particulares) para oferecer um quadro geral de análise. Desse modo, no caso específico do trabalho docente nas IES, adotei a mercantilização crescente da educação como referencial para essa reflexão.

Desenvolvimento do capitalismo, mercantilização do ensino superior no Brasil e intensificação do trabalho docente

O principal marco das mudanças acontecidas no mundo do trabalho que envolveram as atividades docentes situa-se numa crise de acumulação do capital ocorrida em âmbito internacional, por volta do início da década de 1970. Sobre esse período, diversos estudos identificaram uma queda significativa nos ritmos do crescimento das economias capitalistas. Tanto nos países do norte, quanto nos países do sul (nas chamadas economias do "primeiro" e "terceiro" mundos), os índices de crescimento econômico registraram declínio e estagnação. Se nas décadas do pós-guerra o crescimento das economias capitalistas foi geralmente mensurado em torno de dois dígitos, seu vigor começou a desaparecer no final da década de 1960 (IFM, 2005).

Embora os lucros existentes em todo o planeta continuassem a se concentrar cada vez mais nas grandes corporaçóes multinacionais e transnacionais (Baran \& Sweezy, 1978), suas taxas tenderam a diminuir sensivelmente. No campo da reflexão marxista, esta tendência decrescente da taxa de lucro (Marx, 1981) tem sido explicada em relação ao próprio processo de acumulação de capital que, levando ao limite os níveis de produtividade e de competição, faz explodir crises cuja superação, mesmo que temporária, é conseguida através (a) da destruição de parte dos meios de produção existentes, (b) do aumento da taxa de 
A precarização do trabalho docente nas instituiçôes de ensino superior do Brasil...

exploração sobre o trabalho e (c) da expansão do capitalismo sobre ramos recém-abertos ou recém-submetidos ao modo de produção tipicamente capitalista (Marx, 1985). Neste sentido, formas de produção não-capitalistas tornaram-se importantes para o processo de reprodução e acumulação do capital (Luxemburgo, 1984). Se incorporadas ao circuito de produção capitalista, ou seja, se forem mercantilizadas, podem conferir um fôlego adicional para investimentos de todo tipo de capital que se encontra estancado em função de insignificantes taxas de lucro (Braverman, 1987).

No Brasil, este traço foi dos mais salientes na definição do processo de acumulação de capital no país. De acordo com Francisco de Oliveira, principalmente a partir de 1964, a legislação trabalhista foi reconfigurada ${ }^{1}$ com o objetivo de permitir a realização da exploração sobre o trabalho com base na combinação de formas "pré-capitalistas de certos setores da economia - particularmente a agricultura - e o setor emergente da indústria", de tal maneira que o desenvolvimento do capitalismo no Brasil realizava-se sustentado numa complementaridade entre setores da economia ditos "atrasados" e setores ditos "modernos" (Oliveira, 1976, p. 71). Assim, a acumulação de capital se fazia aqui produzida e sustentada por firme arrocho salarial, mecanismo assegurado por determinada legislação trabalhista que "igualava reduzindo - antes que incrementando - o preço da força de trabalho" (idem, ibid., p. 12). Nesse sentido, não haveria nenhuma heterogeneidade sistêmica da força de trabalho no Brasil. Ao contrário disso, empregados qualificados, semiqualificados, não-qualificados e desempregados, longe de comporem o que veio a ser chamado na década de 1970 de "setor informal", eram absolutamente funcionais à economia capitalista. Portanto, a intensificação do trabalho, a precarização, desregulamentação e flexibilização das relações de trabalho, já eram componentes cruciais na equação do desenvolvimento do capitalismo no Brasil.

No contexto histórico mais geral, demarcado a partir da década de 1970 , o capital iniciou a construção de uma solução semelhante a essa para recuperar as antigas taxas de lucro. Tal solução combinou (e ainda combina) diversos fatores numa escala que envolveu desde o barateamento da mão-de-obra por meio da reestruturação dos processos de trabalho e de produção de mercadorias (Hirata, 1993; Antunes, 1999; Alves, 2000), até a transferência monumental dos serviços públicos para 
a esfera da iniciativa privada (Biondi, 1996). Esses expedientes conseguiram reativar, em alguma medida, a capacidade de reprodução do capital.

Este último elemento tem definido a sorte do trabalho docente no Brasil, uma vez que estabeleceu a expansão da educação superior pela via privada e introduziu, nas IES públicas, uma tendência - cada vez mais predominante - de mercantilização do trabalho docente materializada, por exemplo, no crescimento dos cursos de pós-graduação lato sensu pagos. Expressão também de uma ordenada tendência mundial de reforma sobre os direitos sociais e funções do Estado (Chauí, 1999), a política voltada para a mercantilização da educação superior tem sido irradiada para toda a América Latina pela atuação do Banco Mundial ao longo da década de 1990 (World Bank, 1994). Desde então, a idéia de que a educação deveria ser encarada como "Setor dos Serviços Não-Exclusivos do Estado" passou a orientar a ação do Estado em relação às universidades públicas (nos âmbitos federal, estadual e municipal). Uma conseqüência prática dessa política começou a ser mais propriamente observada por volta da primeira metade da década de 1990, quando a relação de matrículas em cursos presenciais oferecidas por IES privadas e públicas aumentou bastante em favor das primeiras. Se até a década de 1980 cada setor ficava com 50\% das matrículas realizadas, no final da década de 1990 esta relação foi de 70\% para $30 \%$ em favor das IES privadas. Dados do MEC/INEP sobre o ano de 2004 indicavam que tal relação prosseguira a mesma tendência verificada nos anos 1990 , atingindo uma proporção de $80 \%$ para $20 \%$ em favor das IEs privadas (Brasil, 2005).

Portanto, a consolidação da matriz do ensino superior nesses termos evidencia uma efetiva mercantilização da educação no Brasil, que se fizera também à custa de muitas modificações na rotina do trabalho docente. A começar pelo crescimento da força de trabalho docente que passou de 109 mil funções, em 1980, para 279 mil, em 2004, um aumento de $154 \%$ ocorrido, principalmente, no setor privado, conforme podemos analisar com base na tabela 1 .

Mesmo relativizando esse aumento de $154 \%$, devido ao fato de que muitos docentes empregados nas instituições privadas de ensino superior foram contabilizados duas ou três vezes (porque trabalham em mais de uma instituição), o crescimento não deixa de ser significativo, 
A precarização do trabalho docente nas instituiçôes de ensino superior do Brasil...

Tabela 1

(Evolução do número de docentes)

\begin{tabular}{lrrrrrrc}
\hline Docentes & 1980 & 1985 & 1989 & 1994 & 1998 & 2003 & 2004 \\
\hline $\begin{array}{l}\text { IES } \\
\text { públicas }\end{array}$ & 60.037 & 64.449 & 70.095 & 75.285 & 83.738 & 88.795 & 93.800 \\
$\begin{array}{l}\text { IES } \\
\text { privadas }\end{array}$ & 49.451 & 49.010 & 57.934 & 66.197 & 81.384 & 165.358 & 185.258 \\
Total & 109.788 & 113.459 & 128.029 & 141.482 & 165.122 & 254.153 & 279.058 \\
\hline
\end{tabular}

Fonte: MEC/INEP (organização do autor).

acompanhando uma inversão da lógica estrutural do ensino superior desde o golpe de 1964, quando a expansão pela via da iniciativa privada tornou-se uma política. Essa dinâmica pode ser facilmente evidenciada pela comparação dos índices referentes às matrículas no ensino superior que, se até a década de 1980 concentraram-se no setor público, passaram a se concentrar no setor privado, principalmente ao longo da década de 1990 (Brasil, 2005). Analisada em relação à evolução dos docentes na ativa das IES públicas e privadas, tal lógica torna-se ainda mais evidente. Se o crescimento da força de trabalho empregada nas IES públicas registrado entre 1980 e 2004 foi de 53\%, nas IES privadas este foi superior a $270 \%$ ! A inversão dessa relação deu-se a partir de 1998 (segundo mandato de FHC) e, certamente, foi preparada pela legislação que estimulou a multiplicação das instituições de ensino privadas e pela política de estagnação das IES públicas, explicitada fundamentalmente no arrocho orçamentário e no represamento de concursos. A tabela 2 representa essa evolução.

Outra característica desse crescimento é a flexibilidade registrada nos regimes de trabalho. Do total de docentes cadastrados pelo censo do INEP (2004), apenas 16,9\% trabalham em regime de dedicação exclusiva. Mesmo se considerarmos como hipótese que tal cifra diz respeito quase que integralmente à realidade das IES públicas, sua repercussão ainda evidenciaria uma grande desregulamentação do trabalho docente, já que representaria - nessa hipótese - apenas 48\% de todos os docentes das IES públicas (Brasil, 2006). E há ainda outros expedientes 
menos ortodoxos de flexibilização da contratação e do regime de trabalho nas IES públicas, como a utilização de alunos de pós-graduação como professores substitutos e a fracassada tentativa do governo FHC de instituir o regime de 12 horas nas IFES. No caso das IES privadas, existem mais de 118 mil docentes em regime "horista", o que representa quase $70 \%$ de todos os docentes ocupados no ensino superior no Brasil. Em relação à legislação educacional que estabeleceu parâmetros de contratação já bastante flexíveis a partir de 1996 (LDB), 7 das 84 universidades públicas não cumprem a exigência de terem pelo menos um terço do corpo docente em regime de tempo integral. Já entre as universidades privadas, esse tipo de transgressão atinge 65 das 86 IES existentes, o que representa mais de $75 \%$ numa situação ilegal.

No que se refere às instituições federais de ensino superior (IFES), o aumento de docentes entre 1980 e 2004 foi raquítico, progredindo de 42.010 para 50.337, o que significou um acréscimo de pouco mais de 8.000 docentes em 24 anos, como está representado na tabela 3 . Assim, o crescimento no setor público aconteceu, principalmente, nas IES estaduais. Enquanto nestas houve um aumento de 153\%, nas IFES esse percentual foi de tímidos 19,8\%.

\section{Tabela 2}

(Evolução do número de docentes - \%)

\begin{tabular}{lccccccc}
\hline Docentes & 1980 & 1985 & 1989 & 1994 & 1998 & 2003 & 2004 \\
\hline IES públicas & 54.6 & 56.8 & 54.7 & 53.3 & 50.7 & 34.9 & 33.6 \\
IES privadas & 45.4 & 43.2 & 45.3 & 46.7 & 49.3 & 65.1 & 66.7 \\
Total & 100 & 100 & 100 & 100 & 100 & 100 & 100 \\
\hline
\end{tabular}

Fonte: MEC/INEP (organização do autor).

A característica principal desse crescimento reside no fato de que muitas das jovens universidades estaduais criadas nesse período já nasceram sob a regra da precarização, exibindo formas "criativas" de contratação. Além dos contratos temporários e efetivos baseados em horas-aula (pagamento por aula e ausência de Plano de Carreira), como é o caso da 
A precarização do trabalho docente nas instituições de ensino superior do Brasil...

Fundação Estadual de Alagoas, tem sido prática corrente o recurso às "bolsas de pesquisa" e "adicionais" por atividade de extensão como forma de remuneração docente (Universidade Estadual do Piauí e as 4 universidades estaduais da Bahia). Mesmo em universidades consolidadas como a UNESP, a expansão deu-se, principalmente, pela "extensão" dos docentes já efetivos para os novos campi e pela contratação de docentes por períodos de três meses, regime de trabalho chamado de professores "conferencistas". Além disso, a grande maioria das universidades estaduais criadas desde o final da década de 1980 carece de infra-estrutura para atividades de pesquisa. Algumas sequer possuem instalações próprias, mas funcionam em prédios adaptados. Desse modo, muitas dessas instituições oferecem apenas o ensino.

\section{Tabela 3}

(Evolução do número de docentes nas IES públicas)

\begin{tabular}{llllllll}
\hline Docentes & 1980 & 1985 & 1989 & 1994 & 1998 & 2003 & 2004 \\
\hline Docentes IFES & 42.010 & 42.087 & 43.397 & 43.556 & 45.611 & 47.709 & 50.337 \\
Docentes IEES & 14.141 & 17.392 & 22.556 & 25.239 & 30.621 & 33.580 & 35.866 \\
Docentes IMES $^{*}$ & 4.186 & 5.020 & 4.142 & 6.490 & 7.560 & 7.506 & 7.597 \\
Total & 60.037 & 64.449 & 70.095 & 75.285 & 83.738 & 88.795 & 93.800 \\
\hline
\end{tabular}

* Municipais

Fonte: MEC/INEP (organização do autor).

Portanto, é certo que tal crescimento da força de trabalho docente foi (e continua sendo) marcado pela flexibilização dos contratos trabalhistas. São essas possibilidades de contratação precária, abertas por práticas constituídas à margem da lei ou mesmo por modificações na legislação trabalhista, que têm feito com que o número de docentes aumente. Nesse sentido, é certo também que, tornado numericamente predominante, o trabalho considerado precário e informal tende a converter-se em medida para todo tipo de trabalho restante. Este é o principal fundamento histórico do processo que atravessamos. É nesse "Espelho de Próspero" às avessas que, por exemplo, os docentes considerados trabalhadores "formais" começam a se verem refletidos, sem necessariamente 
conseguirem entender as formas atuais do seu próprio trabalho como expressão da dominação capitalista.

Visualizar a totalidade desse processo requer adotar o pressuposto de que, para além da precarização do trabalho docente expresso nas "velhas" e "novas" formas de contratação, muitas mudanças foram introduzidas na rotina das atividades de ensino, pesquisa e extensão, desde, pelo menos, o governo Collor de Melo. Do ponto de vista do capital, trata-se de aumentar o trabalho docente em extensão e intensidade. Esse processo ainda inconcluso é objetivado na mercantilização da educação pública e, nesse sentido, progride combinado à transferência dos aportes patrimoniais, financeiros e humanos públicos, para a iniciativa privada, por meio, principalmente, de alterações na superestrutura jurídica do Estado. Além do carreio direto de verbas públicas para a iniciativa privada, a exemplo do que tem representado o Programa Universidade Para Todos (Prouni) (Leher, 2004) e do que prometem as parcerias público-privadas (Jucá, 2004), compõem o núcleo estratégico dessas alterações os mecanismos desenvolvidos para intensificar o trabalho e relacioná-lo às demandas de mercado (Chauí, 1999). Desse modo, ao mudar as formas institucionais do trabalho docente força-se a mudança da rotina do trabalho docente.

No âmbito do trabalho docente nas IFES, uma mudança nas regras da remuneração por parte do MEC (governo FHC) no ano de 1998, durante uma greve que já se estendia por três meses, estabeleceu uma gratificação por produção chamada de Gratificação de Estímulo à Docência (GED) (Pinto, 2000). Teriam direito à gratificação em seu valor integral os docentes que atingissem 120 pontos contabilizados em relação a uma série de atividades de natureza acadêmica. Em suma, a obtenção dessa pontuação dava-se pelo aumento de horas-aula semanais, o que motivou muitos professores a aumentarem o número de aulas ministradas. Além disso, a essa estrondosa intensificação do trabalho docente associou-se também um significativo aumento do número de alunos em relação aos docentes, verificado a partir de 1994, como representa a tabela 4. Analisando os dados dessa tabela, tal aumento passou de 8 alunos por professor, em 1998, para 12 alunos por professor, em 2004.

No plano geral das IES públicas, essa intensificação do trabalho também aconteceu devendo-se, principalmente, ao represamento de concursos ao longo desses últimos 15 anos, fato que confirma como 
A precarização do trabalho docente nas instituiçôes de ensino superior do Brasil...

constante a racionalização de feição neoliberal dos orçamentos públicos em todos os Estados do Brasil. Analisando os dados da tabela 5, verifica-se que a relação de 6 alunos para cada docente, no ano de 1980, aumentou para 12 alunos por cada docente, no ano de 2004.

\section{Tabela 4}

(Relação docentes e matrículas nas IFES)

\begin{tabular}{lccccccc}
\hline Anos & 1980 & 1985 & 1989 & 1994 & 1998 & 2003 & 2004 \\
\hline IFES & 42.010 & 42.087 & 43.397 & 43.556 & 45.611 & 47.709 & 50.337 \\
Matrículas graduação* & 305.099 & 314.102 & 301.535 & 349.790 & 392.873 & 567.101 & 567.101 \\
\hline
\end{tabular}

"Considerados apenas os matriculados em cursos de graduação presenciais.

Fonte: MEC/INEP (organização do autor).

\section{Tabela 5}

(Relação docentes e matrículas nas IES públicas)

\begin{tabular}{llllllll}
\hline Docentes & 1980 & 1985 & 1989 & 1994 & 1998 & 2003 & 2004 \\
\hline IES públicas & 60.037 & 64.449 & 70.095 & 75.285 & 83.738 & 88.795 & 93.800 \\
Matrículas graduação* & 403.841 & 433.957 & 459.335 & 571.608 & 700.539 & 1.136 .370 & 1.178 .328 \\
\hline
\end{tabular}

* Considerados apenas os matriculados em cursos de graduação presenciais.

Fonte: MEC/INEP (organização do autor).

\section{Produtivismo acadêmico e precarização do trabalho docente}

Marilena Chauí chegou a adjetivar esse processo como "insano" porque o "funcionamento" das instituições de ensino superior, particularmente as públicas, teve sua autonomia castrada à medida que suas metas, objetivos, índices de produção, e a própria gestão passaram a ser informados de fora da universidade. Uma grave conseqüêencia disso, ainda na fala dessa autora, foi um embotamento da reflexão daqueles que vivenciam e fazem a universidade:

(...) o aumento insano de horas-aula, a diminuição do tempo para mestrados e doutorados, a avaliação pela quantidade das publicaçóes, 
colóquios e congressos, a multiplicação de comissões e relatórios etc. virada para seu próprio umbigo, mas sem saber onde este se encontra, a universidade operacional opera e por isso mesmo não age. (Chauí, 1999, p. 3)

Assim, a pressão exercida para aumentar a quantidade de trabalho dentro da jornada de 40 horas tem se concretizado, principalmente, alicerçada na idéia de que os docentes devem ser "mais produtivos", correspondendo à "produção" a quantidade de "produtos" relacionados ao mercado (aulas, orientações, publicações, projetos, patentes etc.) expelidos pelo docente. Por um lado, evidencia esse processo o direcionamento empresarial da ciência, tecnologia, pesquisa e desenvolvimento, presente nos editais dos órgãos de fomento à produção científica. Cada vez mais, o CNPq e as fundações estaduais de apoio à pesquisa têm convertido seus recursos para pesquisas e estudos que aparelhem e potencializem a capacidade de reprodução do capital, desenvolvendo uma razão instrumental que pode ser facilmente verificada no caráter dos editais divulgados. ${ }^{2} \mathrm{O}$ perfil de pesquisa que escorre caudalosamente desses editais termina por ditar o padrão para a produção acadêmica em geral. Uma das consequiências desse processo é que a qualidade da produção acadêmica passa então a ser mensurada pela quantidade da própria produção e por valores monetários que o docente consegue agregar ao seu salário e à própria instituição.

Essa dinâmica tem representado, na rotina do trabalho docente, não apenas uma assimilação desse padrão de produção (que em realidade é de produtividade), mas uma necessidade de criar as condiçôes para a realização dessa produção já que, institucionalmente, os meios de produção acadêmicos (livros, laboratórios, computadores, equipamentos, bolsas etc.) foram (e continuam sendo) concentrados e disponibilizados para as áreas que conseguem inverter ciência e tecnologia para o capital. O resultado dessa política tem se materializado num crescimento cavalar da produção e da produtividade acadêmica, cujo objetivo se encerra no próprio ato produtivo, isto é, ser e sentir-se produtivo. A evidência desse processo é facilmente constatada, conforme depoimento do próprio diretor de avaliação da CAPEs: “(...) Cada programa de pós-graduação, muitas vezes cada departamento de graduação, quer editar a sua revista. Quem vai ler isto? É óbvio que se você publica artigos que não são lidos é um desastre" (Ribeiro, 2006, p. 42). 
A precarização do trabalho docente nas instituiçôes de ensino superior do Brasil...

À medida que os recursos disponíveis para a pesquisa são canalizados pelas áreas consideradas "rentáveis", eles passam a ser usados privativamente dentro da própria instituição: laboratórios, computadores, salas, auditórios e equipamentos que servem apenas e exclusivamente aos grupos, núcleos e centros de pesquisa construídos às expensas do dinheiro público (propriamente os editais) e em parceria com empresas (ADUSP, 2002). Cada vez mais privatizados os meios de produção do trabalho docente (e do conhecimento), resta aos professores desenvolverem suas próprias condições de trabalho, combinando "competição", "empreendedorismo" e "voluntarismo". A começar pelo "empreendedorismo", um dos mais antigos e eficientes artefatos ideológicos do capital voltado para convencer e converter ao trabalho homens e mulheres, há exemplos de ímpar vulgaridade sobre como a instrumentalidade do comportamento adequado à lógica produtivista é defendida e divulgada, conforme encontra-se explicitado no Editorial da revista Profissão Mestre, de abril de 2006:

(...) A sociedade da informação e da tecnologia muda o perfil do trabalhador e a realidade do emprego: pesquisas apontam que a cada dois postos de trabalho no Brasil, um é formal e outro é informal; entre 16 e 25 milhões de trabalhadores são autônomos ou empreiteiros independentes; atualmente os maiores empregadores não são as megacorporações e, sim, as agências de trabalho temporário; (...) O mundo da educação não está isento a essa nova realidade. Escolas e professores sofrerão o impacto dessa nova tendência econômica e social. É por essas e outras que a equipe das revistas Profissão Mestre e Gestão Educacional está lançando o Kit Professor S.A. Um material exclusivo que servirá como uma bússola para guiálo através desse cenário de incertezas. (Clebsch, 2006, p. 4)

Uma das principais manifestações desse empreendedorismo tem sido a produção em série de cursos de pós-graduação lato sensu pagos, ${ }^{3}$ como forma de recompor os parcos salários e de estruturar as condições de trabalho pela compra de equipamentos, livros e até mesmo pela construção de área física. Desta realidade não escapou nem mesmo uma das mais estruturadas universidades públicas do país, a USP. A proliferação de cursos lato sensu não somente é crescente e representativa, como também, em alguns casos, pode coibir a expansão dos cursos stricto sensu, como esclarece a jornalista Tatitana Lotierzo:

Os mBAs (Master of Bussness Administration, como são chamados na área de Administração), segundo os relatórios anuais da fundação, são "cursos 
de pós-graduação". O MBA em Administração tem cinco turmas, com 36 alunos cada, o que totaliza 180 alunos. Os valores cobrados estão entre os mais altos da USP: matrícula de $\mathrm{R} \$ 780$ e 23 parcelas de $\mathrm{R} \$ 667$ (o curso é ministrado aos sábados e dura dois anos), o que totaliza $\mathrm{R} \$$ 16.121 por aluno. Esse curso, sozinho, gera para a FUNDACE uma receita anual de R \$ 1,45 milhão. Enquanto isso, a secretaria de pós-graduação da FEA-RP informa que há duas vagas para mestrado em Administração e uma para doutorado. Portanto, são três vagas de pós-graduação stricto sensu, gratuita, contra 180 para o lato sensu. No total, os cursos pagos da FUNDACE têm cerca de 600 alunos matriculados anualmente. (Lotierzo, 2003, p. 81-82)

Somada aos cursos de especialização há também a venda de diversos tipos de serviços por meio das fundações ditas de "apoio universitário" e por regulamentos internos das IES públicas, que prevêem a flexibilização do regime de dedicação exclusiva dos docentes. Assim, ganham lugar dentro das universidades, diversos escritórios - e consultórios no caso dos médicos - especializados em prestar consultorias e desenvolver produtos. Nessa via, o trabalho docente, concebido como extensão universitária, é mercantilizado. O resultado dessas intervenções tende a tornar esses docentes e as universidades cada vez mais dependentes dessas práticas, convertendo-os, muitas vezes voluntariamente, em captadores de recursos extra-orçamentários. A esse respeito, torna-se representativa a observação de Rogério Guerra, do departamento de Psicologia da UFSC:

(...) Antes, os profissionais deveriam recorrer aos almoxarifados das instituiçōes para obter itens necessários ao seu trabalho, como papel para impressão de textos, canetas, material de limpeza ou itens mais específicos, como álcool, éter, reagentes e vidrarias. Atualmente, os professores devem elaborar projetos de pesquisa ou de extensão universitária para o aparelhamento institucional. (Guerra, 2005, p. 8)

Alinha-se a esse aspecto financeiro, de forte apelo e impacto ideológico, uma ressocialização dos docentes com base num padrão produtivista, um tipo de "cultura do desempenho" também percebido nos ensinos fundamental e médio (Santos, 2004). O adensamento e a intensificação do trabalho são traduzidos em números que estruturam as diversas avaliaçōes ditas institucionais. Assim, do mesmo modo que os cursos de graduação têm sido classificados e hierarquizados desde o "Provão" (transmutado em SINAES), e os programas e cursos de pós-graduação têm sido referenciados 
A precarização do trabalho docente nas instituiçôes de ensino superior do Brasil...

em conceitos de 3 a 7, a produção docente também tem sido esquartejada, mensurada, tipificada e classificada por critérios quantitativos. Os artigos científicos são valorizados de acordo com o periódico que o veicula, isto é, caso esteja indexado internacionalmente ou pelo "Qualis/ CAPES" (indexador nacional oficial que classifica os periódicos em 9 níveis). Nesse "vale quanto pesa", o próprio docente é "valorizado" pela inserção na pós-graduação, pelo número de orientações, artigos e livros publicados e, principalmente, pela "bolsa produtividade em pesquisa" que consegue por méritos próprios. De fato, a inclusão nesse sistema opera uma diferenciação entre os docentes de maneira a estimular a conformação de uma "elite" definida como tal pelo desempenho conseguido nos editais de pesquisa, nas bolsas concedidas, nos artigos publicados, enfim, pela pontuação atingida no escore da produtividade acadêmica. Aparentemente, esse docente tende a acreditar que o seu desempenho é excepcional, fruto de algum tipo de genialidade que o distingue de seus pares. Em essência, geralmente passa despercebido que sua suposta genialidade é eleita por critérios definidos pelos interesses do mercado e que, ela mesma, é produto da própria escassez dos recursos que se tornam alvo de disputa. Por esse processo, surge uma identidade docente diferenciada por status e prestígio decorrentes da escassez e do caráter mercantil dos recursos para pesquisa. Nessa "cultura da produtividade", explica Leopoldo de Méis, do Instituto de Ciências Biomédicas da Universidade Federal do Rio de Janeiro, “(...) Ser ou não ser um cientista reconhecido é um ritual que se repete constantemente, a cada edital. Se parar de publicar, você perde a bolsa, não ganha mais auxílio. É ejetado do sistema, não interessa o que você fez no passado. O que interessa são os últimos dois, três anos." (Chrispiano, 2006, p. 28).

Esse drama hamletiano, vivenciado cotidianamente pelos docentes, tem reforçado um sistema de avaliação do trabalho docente que, ano a ano, alarga o limite da escala de mensuração da produtividade acadêmica. Em algumas áreas do conhecimento, os critérios utilizados já banalizaram os termos de classificação mais universais tais como a indexação, introduzindo como medida o tempo de carência para artigos e comunicações, estabelecendo prazos de validade que, quando ultrapassados, fazem "caducar" a produção acadêmica.

A cada volta desse parafuso, os professores tornam-se reféns dos critérios de produtividade que, ao instituírem novos valores no espaço universitário, ressocializam todas as atividades componentes do trabalho 
acadêmico, permitindo e legitimando a invasão crescente do tempo do trabalho na vida dos docentes (Campos et al., 2004). Envolvidos nesse ambiente de intensa competitividade - onde é uma constante o estímulo ao espírito empreendedor e competitivo - torna-se difícil a produção de uma identidade que se dê pela percepção de que é preciso organização e mobilização para mudança desse sistema. Ao contrário, o padrão que é socializado deita raízes em práticas e valores individualistas cuja racionalidade se expressa na diferença entre ser produtivo e improdutivo. A competição é naturalizada, tornando-se a regra. A escassez de recursos para pesquisa (e para o trabalho docente em geral) também é naturalizada e se transforma em realidade que avaliza a "competência" dos que conseguem acessar tais recursos. E o resultado dessa dinâmica traz conseqüências comuns ao mundo do trabalho, tais como o estresse, o estado permanente de cansaço, a depressão e até o suicídio (Méis, 2003). Estudo realizado com professores e alunos de cursos de pós-graduação stricto sensu de doze instituições, avaliados em seis e sete pela CAPES, concluiu que o sentimento de desapontamento com suas carreiras é uma constante à medida que não conseguem um desempenho materializado em publicaçôes considerado satisfatório. Assim, é emblemática a fala de um dos professores entrevistados nesse estudo: “(...) Quando um jornal não aceita seu paper, seu sentimento não é o de que seu paper não foi aceito, mas de você mesmo é que foi rejeitado. (...) Eles olham para você como se você não devesse estar ali” (idem, ibid., p. 1139).

Essa cultura da produtividade - fator da ressocialização do docente no espaço acadêmico - é transferida para os alunos da graduação e da pós-graduação que passam a receber a pressão para que sejam produtivos sob quaisquer condições. A ponta desse iceberg foi vista pela primeira vez quando os prazos para conclusão do mestrado e do doutorado (bem como os prazos das bolsas para esses cursos) sofreram seguidas reduções. As bolsas para mestrado, por exemplo, tiveram redução de 3 para 2 anos e meio, no início da década de 1990, e de 2 anos e meio para 2 anos, no final dessa mesma década. Nessa nova ossatura institucional, os mestrandos e doutorandos quase sempre recebem pressão de seus orientadores e dos programas (que pleiteiam sempre a melhor pontuação na CAPES) para cumprirem esses prazos a despeito da qualidade final de seus trabalhos. Na visão de Elisa de Campos Borges, presidente da ANPG, 
A precarização do trabalho docente nas instituiçôes de ensino superior do Brasil...

(...) A quantidade exagerada de publicações para fins de pontuação vem promovendo um ambiente demasiadamente competitivo dentro da academia, nocivo às iniciativas criadoras dos estudantes e dos pesquisadores. Todos os alunos de pós-graduação vivem em seu cotidiano a dificuldade de conseguir publicar textos científicos em muitas revistas, pois o acesso a muitas delas é restrito a determinados pesquisadores, universidades, programas e temas. (Chrispiano, 2006, p. 29)

Em algumas áreas do conhecimento, a reprodução desse comportamento atinge não somente os alunos da pós-graduação, mas repercute também entre alunos da graduação que sofrem, já desde cedo, a pressão para serem competitivos. A esse respeito, estudo realizado com alunos de diversos cursos de graduação da Universidade Federal de São Paulo (UNIFESP), entre 1996 e 2003, revela que o diagnóstico de cerca de 10 diferentes enfermidades relacionadas à saúde mental tem sido recorrente nos alunos de graduação (Nogueira-Martins et al., 2004).

\section{Considerações finais}

Deslindar esses fios alinhavados que dão os contornos do "novo" docente tem sido difícil, principalmente porque a grande maioria daqueles que se opõem a esse sistema tende a ser vista como "improdutiva". Por outro lado, a crítica realizada acerca do sistema produtivista, que tem sido implementado com base, principalmente, em órgãos de fomento e de avaliação de pesquisa (como CAPES, CNPq e seus congêneres estaduais), tende a ver todos os docentes que estão presos aos cordōes da produtividade acadêmica como agentes conscientes do sistema e, consequentemente, como produtores de suas próprias experiências em condições escolhidas por eles mesmos. Esquece-se que as circunstâncias em que muitos docentes estão escolhendo o produtivismo são historicamente determinadas, obviedade que deveria desmistificar tal escolha como espontânea. Em grande medida, a produtividade (recompensada monetária e simbolicamente) representa a perda da autonomia intelectual, a perda do controle sobre o processo de trabalho, a forma atual da subsunção do trabalho intelectual à lógica do capital. Como os primeiros trabalhadores que internalizaram uma prática econômica com base na frugalidade, poupança e sentimento de compensação espiritual nos começos do capitalismo, enfrentamo-nos hoje com uma dinâmica muito semelhante. Por isso, o risco de não decifrarmos essa realidade e desenvolvermos os melhores instrumentos de luta para 
combatê-la reside, como foi na infância da luta de classes, em tornarmo-nos cada vez mais prisioneiros dessa lógica, como nossos "próprios cárceres".

Assim contextualizadas, as condições históricas da precarização do trabalho docente nas IES no Brasil carecem de problematização, reflexão e denúncia sistemáticas. Ordenam-se a essa ação iniciativas de combate ao produtivismo que incidam na superestrutura jurídica do Estado. Desse modo, a luta contra o enraizamento da Lei de Inovação Tecnológica nas IES públicas e as diversas regulamentações afetas ao produtivismo pode e deve ser travada em cada órgão colegiado das universidades. A problematização e a redefinição dos critérios de avaliação institucional do trabalho docente podem abrir possibilidades para a redistribuição dos recursos e a necessária ampliação destes com base na compreensão de que, assim como todos os professores têm o direito a condições adequadas para realização de suas aulas, devem ter direito também a recursos para suas pesquisas. Enfrentar esses desafios significa lutar para superar as dificuldades mais salientes nesse processo de alienação do trabalho.

Recebido em setembro de 2006 e aprovado em maio de 2007.

\section{Notas}

1. A quebra da estabilidade no emprego (onde ela existia, obviamente), por meio da criação do Fundo de Garantia por Tempo de Serviço (FGTS), instituído em 1966, foi uma das medidas que integraram essa reconfiguração.

2. Neste ponto, recorri aos relatórios sobre "Ciência e Tecnologia" dos Congressos e CONADs do Sindicato Nacional dos Docentes das Instituiçôes de Ensino Superior (ANDES-SN), realizados nos últimos 15 anos. Tais relatórios estão disponíveis em: <http://www.andes.org.br>. Conferir também "A propósito da regulamentação da Lei de Inovação Tecnológica: por quem os sinos dobram" (ANDES-SN, 2006b).

3. Tais informações foram extraídas dos relatórios sobre "Política Educacional" dos Congressos e CONADS do ANDES-SN, realizados nos últimos 15 anos. Essas informaçōes dizem respeito tanto às IFES, quanto a muitas IEES. Os relatórios estão disponíveis em: <http://www.andes.org.br>. Conferir também: "Dossiê Nacional 1, Publicação Especial do ANDES-SN" (ANDES-SN, 2006a) e o Dossiê Especial "Cursos Pagos ameaçam caráter público da USP” (ADUSP, 2002).

\section{Referências bibliográficas}

ALVES, G. O novo (e precário) mundo do trabalho: reestruturação produtiva e crise do sindicalismo. São Paulo: Boitempo, 2000. 
A precarização do trabalho docente nas instituiçôes de ensino superior do Brasil...

AMARAL, N.C. Financiamento da educação superior: Estado x mercado. São Paulo: Cortez; Piracicaba: Unimep, 2003.

ANTUNES, R. Os sentidos do trabalho: ensaio sobre a afirmação e a negação do trabalho. São Paulo: Boitempo, 1999.

ASSOCIAÇÃO DOS DOCENTES DA UNIVERSIDADE DE SÃO PAULO (ADUSP). Cursos pagos ameaçam caráter público da ADUSP. Revista da ADUSP, São Paulo, n. 27, out. 2002.

AUGUSTO, M.H.O.G. As reformas educacionais e o 'choque de gestão': a precarização do trabalho docente. In: REUNÃO ANUAL DA ANPEd, 28., 2005, Caxambú. Anais... Caxambú: ANPEd, 2005.

BARAN, P.; SWEEZY, P. Capitalismo monopolista. 3. ed. Rio de Janeiro: Zahar, 1978.

BIONDI, A. O Brasil privatizado. São Paulo: Perseu Abramo, 1996.

BRASIL. Ministério da Educação. Instituto Nacional de Estudos e Pesquisas Educacionais. Sinopse do Cadastro Nacional de Docentes da Educação Superior. Brasília, DF: MEC/INEP, 1980. Disponível em: <http:// www.inep.gov.br/>. Acesso em: 17 abr. 2005.

BRASIL. Ministério da Educação. Instituto Nacional de Estudos e Pesquisas Educacionais. Cadastro Nacional de Docentes da Educação Superior. Brasília, DF: MEC/INEP, 2005. Disponível em: <http://www.inep.gov.br/>. Acesso em: 27 abr. 2006.

BRAVERMAN, H. O mercado mundial. In: Braverman, H. Trabalho e capital monopolista: a degradação do trabalho no século XX. Rio de Janeiro: Guanabara, 1987. p. 231-141.

CAMPOS, M.B.L. et al. O professor universitário: um estudo sobre atividade acadêmica e tempo livre. Universidade \& Sociedade, Brasília, DF, v. 14, n. 34, p. 67-74, out. 2004.

CHAUÍ, M. A universidade operacional. Folha de S. Paulo, São Paulo, 9 maio 1999. Caderno Mais!

CHAVES, V.L.J. As feiçôes da privatização do público na educação superior brasileira: o caso da UFPA. 2005. Tese (Doutorado) - Universidade Federal de Minas Gerais, Belo Horizonte. 
CHRISPIANO, J. Todo poder à avaliação. Revista da ADUSP, São Paulo, n. 36, p. 26-35, jan. 2006.

CLEBSCH, J. Editorial. Profissão Mestre, Curitiba, p. 4, abr. 2006.

DAL ROSSO, S. "Orelhas secas": condições de trabalho de contratados pelo serviço público. Universidade \& Sociedade, Brasília, DF, v. 10, n. 23, p. 141-152, fev. 2001.

GENTILI, P.; LEVY, B. Espacio público y privatización del conocimiento: estudios sobre políticas universitarias en América Latina. Buenos Aires: CLACSO, 2005.

GUERRA, R.F. Impressões sobre a universidade insalubre. Plural, Florianópolis, v. 11, n. 14, p. 4-13, 2005.

HIRATA, H. (Org.). Sobre o modelo japonês. São Paulo: EDUsp, 1993.

INSTITUTE FOR MANUFACTURING (IFM). Gross domestic product. [online]. Disponível em: <http:// www.ifm.org>.

INÁCIO, A.; WAGNER, J.L. A aposentadoria do professor que trabalhou em condições insalubres sob o regime da CLT. Universidade \& Sociedade, Brasília, DF, v. 13, n. 30, p. 45-47, jun. 2003.

JUCÁ, C.V. Os contratos de parceria público privada. In: A DESTRUIÇÃO: o que está em jogo? Campinas: ADUNICAMP, 2004. p. 60-65.

LEHER, R. Por que tamanho apreço pela privatização da educação superior?. In: ASSOCIAÇÃO DOS DOCENTES DO PARA (ADUFPA). Reforma da educação superior ou destruição da universidade pública? Belém: ADUFPA, 2004. p. 92-109.

LOTIERZO, T. Lucratividade "sem fins lucrativos": em 5 anos, cursos pagos triplicam a receita da FUNDACE. Revista da ADUSP, São Paulo, n. 31, p. 74-82, nov. 2003.

LUXEMBURGO, R. A reprodução do capital e seu meio. In: LuXEMBURGO, R. A acumulação do capital: contribuição ao estudo econômico do imperialismo. São Paulo: Abril Cultural, 1984. v. 2, p. 17-30.

MARX, K. Lei: tendência a cair da taxa de lucro. In: MARX, K. O capital: livro 3. Rio de Janeiro: Civilização Brasileira, 1981. v. 4, p. 241-265. 
A precarização do trabalho docente nas instituiçôes de ensino superior do Brasil...

MARX, K. A lei geral da acumulação capitalista. In: MARX, K. O Capital: livro 1. São Paulo: Nova Cultural, 1985. v. 2, p. 187-259.

MÉIS, L. et al. The growing competition en Brazilian science: rites of passage, stress and burnout. Brazilian Journal Medical and Biological Research, Ribeirão Preto, n. 36, p. 1135-1141, 2003.

NOGUEIRA-MARTINS, L.A. et al. The mental health of graduate students at the Federal University of São Paulo: a preliminary report. Brazilian Journal of Medical and Biological Research, Ribeirão Preto, n. 37, p. 1519-1524, 2004.

OLIVEIRA, D.A. A reestruturação do trabalho docente: precarização e flexibilização. Educação \& Sociedade, Campinas, v. 25, n. 89, p. 1127 1144, set./dez. 2004.

OLIVEIRA, F. A economia brasileira: crítica à razão dualista. In: SELEÇÕES CEBRAP 1. São Paulo: Brasiliense, 1976.

OLIVEIRA, G. Trabalho flexibilizado na universidade. Universidade \& Sociedade, Brasília, DF, v. 6, n. 11, p. 48-56, jun. 1996.

PINTO, M.B. A subordinação do trabalho docente à lógica do capital. Outubro, São Paulo, n. 4, p. 17-24, 2000.

PINTO, M.B. Precarização do trabalho docente: a educação como espaço de acumulação do capital. Universidade \& Sociedade, Brasília, DF, v. 11, n. 27 , p. 55-61, jun. 2002.

RIBEIRO, R.J. Entrevista. Revista ADUSP, São Paulo, n. 36, p. 36-51, jan. 2006.

SANTOS, L.L.C.P. Formação de professores na cultura do desempenho. Educação \& Sociedade, Campinas, v. 25, n. 89, p. 1145-1157, set./dez. 2004.

SILVA JUNIOR., J.R. Pragmatismo e populismo na educação superior nos governos FHC e Lula. São Paulo: Xamã, 2005.

SINDICATO NACIONAL DOS DOCENTES DAS INSTITUIÇÕES DE ENSINO SUPERIOR (ANDES-SN). Dossiê Nacional 1: descontrole e ilegalidades marcam atuação das fundações 'de apoio' no Brasil todo. Brasília, DF: ANDES-SN, 2006a. 
SINDICATO NACIONAL DOS DOCENTES DAS INSTITUIÇÕES DE ENSINO SUPERIOR (ANDES-SN). A propósito da regulamentação da Lei de Inovação Tecnológica: por quem os sinos dobram. Brasília, DF: ANDES-SN, 2006b.

WORLD BANK. La enseñanza superior: las leciones derivadas de la experiencia. Washington, DC, 1994. Disponível em: <http:// wbln0018.worldbank.org/>. 